\title{
Electro-Catalytic Production of Lactulose: Statistical Modeling and Experimental Validation
}

\author{
Amara Aït Aissa ${ }^{1,2} \&$ Mohammed Aïder ${ }^{1,2}$ \\ ${ }^{1}$ Department of Soil Sciences and Agro-Food Engineering, Université Laval, Quebec, Canada \\ ${ }^{2}$ Institute of Nutrition and Functional Foods (INAF), Université Laval, Quebec, Canada \\ Correspondence: Mohammed Aïder, Department of Soil Sciences and Agro-Food Engineering, Université Laval, \\ Quebec, Canada. E-mail: mohammed.aider@fsaa.ulaval.ca
}

Received: October 15, 2013 Accepted: November 15, 2013 Online Published: December 30, 2013

doi:10.5539/jfr.v3n1p70

URL: http://dx.doi.org/10.5539/jfr.v3n1p70

\begin{abstract}
Full factorial experimental design was used to optimize the operating conditions of lactose converting into lactulose under electro-activation conditions. The ANOVA showed a high correlation coefficient $\mathrm{R}^{2}(0.9889)$ and a low root mean square error $(1.4 \pm 0.15 \%)$ values for the regression model of the experimental design, indicating the good predictive nature of the model. The obtained results after optimisation showed that the optimum electro-isomerization conditions are the electric current of $300 \mathrm{~mA}$, temperature of $10{ }^{\circ} \mathrm{C}$, and reactor configuration in which a cation exchange membrane separated the central compartment from the cathodic one in which the electro-isomerization reaction was conducted. According to the optimized conditions, the maximum lactose conversion into lactulose was $30 \pm 1.23 \%$. As by-products of the electro-activation, only small amounts of galactose were observed.
\end{abstract}

Keywords: lactose, lactulose, electro-activation, isomerisation

\section{Introduction}

Lactulose (4-O-B-D-Galactopyranosyl-D-Fructose) is a prebiotic which can be produced by isomerization of lactose under alkaline conditions. Since its discovery my Montgomery and Hudson in 1930, lactulose was extensively studied from chemical, process synthesis and applications points of view. Lactulose production is possible by chemical and enzymatic methods. Both of them have serious limits. The chemical synthesis is costly because of the low isomerization yield and the need for several purification steps. The enzymatic synthesis is also expensive because of the cost of the enzymes and the limited times or reusing them. Recently, electro-activation of lactose solution has been shown to be highly promising, safe and economic green technology for lactulose production (Aït Aissa \& Aïder, 2013). It is based on electrochemical reactions at the cathode/solution interface. The oxydo-reduction reactions at this interface generate highly reactive alkaline medium which is extremely favourable for lactose isomerization into lactulose. The accumulated knowledge on lactulose production can be successfully used to design optimal process for lactulose synthesis following lactose electro-activation. In this context, rational experimental design can be used by optimising the main involved experimental conditions. Moreover, the necessity of optimizing lactulose production is justified by the fact that the global demand for this prebiotic is constantly growing, it finds uses in feed and functional food as well as in the pharmaceutical industry as a carrier of medicines (Paseephol, Darryl, Small, \& Sherkat, 2008).

Experiments are performed by investigators in virtually all fields of inquiry, usually to discover something about a particular process or system. A designed experiment is a test or series of tests in which purposeful changes are made to the input variables of a process or system so that we may observe and identify the reasons for changes in the output response (Tagushi et al., 1999). The process or system under study can be represented by the model shown in Figure 1 (Wu \& Hamada, 2000; Siomina \& Ahlinder, 2008). One can usually visualize the process as a combination of different independent variables that transform some input data into outputs or observable responses. An experimental design is a plan for applying different experimental conditions to experimental units to determine how such conditions affect some measure of behaviour, usually known as the criterion or dependent variable. The objectives of the experiment may include the following: Determining which variables are most influential on a response $\mathrm{Y}$; determining where to set the $\mathrm{X}$ variables so that $\mathrm{Y}$ is almost always near the desired nominal value; and determining how to set the influential $\mathrm{X}$ so that variability in $\mathrm{Y}$ is small; determining how to 
set the controllable $X$ so that the effects of the uncontrollable variables $Z_{1}, Z_{2}, \ldots, Z_{q}$ are minimized. The fundamental principles in design of experiments are solutions to the problems in experimentation posed by the two types of nuisance factors and serve to improve the efficiency of experiments (Eriksson et al., 2008; Zhang, 2011; Damyanov \& Germanova-Krasteva, 2012).

The aim of this study was to develop a statistical model to optimize the process of lactulose production following electro-activation of lactose solution and to validate the model under laboratory experimental conditions. A full factorial experimental design was used to investigate the effect of applied electrical current, working temperature and electro-activation reactor configuration on the isomerization of lactose to lactulose by electro-activation.

\section{Statistical Modeling of the Process}

\subsection{Mathematical Formulation}

In this work, a full factorial design $2^{\mathrm{k}}$ was used with $\mathrm{k}$ factors $(\mathrm{k}=3)$, with each one at two levels. These levels will be designated by the digits -1 (low), and +1 (high). Each treatment combination in the $2^{3}$ design will be denoted by three digits, where the first digit indicates the level of the factor $\mathrm{X}_{1}$, the second digit indicates the level of the factor $\mathrm{X}_{2}$, and the third digit indicates the level of the factor $\mathrm{X}_{3}$. The polynomial equation of the third order in equation 1 was used to model the response variable $\hat{\mathrm{y}}$ as a function of the input factors $\mathrm{X}$ 's (Montgomery, 1976).

$$
\hat{y}=b_{0}+\sum_{j=1}^{k} b_{j} X_{j}+\sum_{i=1}^{k} \sum_{\substack{j=1 \\ i \neq j}}^{k} b_{i j} X_{i} X_{j}+\sum_{i=1}^{k} \sum_{\substack{j=1 \\ i \neq j \neq p}}^{k} \sum_{p=1}^{k} b_{i j p} X_{i} X_{j} X_{p}+\sum_{j=1}^{k} b_{j j} X_{j}^{2}+\ldots
$$

For $\mathrm{k}=3$ (three parameters), the regression equation is given in the Equation 2.

$$
\hat{\mathrm{y}}=\mathrm{b}_{0}+\mathrm{b}_{1} \mathrm{X}_{1}+\mathrm{b}_{2} \mathrm{X}_{2}+\mathrm{b}_{3} \mathrm{X}_{3}+\mathrm{b}_{12} \mathrm{X}_{1} \mathrm{X}_{2}+\mathrm{b}_{13} \mathrm{X}_{1} \mathrm{X}_{3}+\mathrm{b}_{23} \mathrm{X}_{2} \mathrm{X}_{3}+\mathrm{b}_{123} \mathrm{X}_{1} \mathrm{X}_{2} \mathrm{X}_{3}
$$

Each experimental value $\mathrm{y}_{\mathrm{i}}$ is prone to the random errors $\varepsilon_{\mathrm{i}}$ with normal distribution as shown in Equation 3.

$$
\mathrm{y}_{\mathrm{i}}=\hat{\mathrm{y}}+\varepsilon_{\mathrm{i}}
$$

Where:

$\mathrm{b}_{0}$ is the overall mean response,

$b_{j}$ is the main effect for factor $(i=1,2, \ldots, k)$

$\mathrm{b}_{\mathrm{jj}}$ is the quadratic effect for factor $(\mathrm{i}=1,2, \ldots, \mathrm{k})$

$b_{i j}$ is the two-way interaction between the $i^{\text {th }}$ and $j^{\text {th }}$ factors, and

$b_{i j p}$ is the three-way interaction between the $\mathrm{i}^{\text {th }}, \mathrm{j}^{\text {th }}$, and $\mathrm{p}^{\text {th }}$ factors

$\mathrm{y}_{\mathrm{i}}$ is the experimental response

$\varepsilon_{\mathrm{i}}$ is the random error component.

Since there are $2^{3}$ combinations, there are 7 degrees of freedom between these combinations. Each main effect has two degrees of freedom, each two-factor interaction has four degrees of freedom, and the three-factor interaction has eight degrees of freedom. With the consideration of $n$ replicates ( $n=3$ in this study), there will be $\left(n 2^{3}-1\right)$ total degrees of freedom and $\left(2^{3}(n-1)\right)$ degrees of freedom for error (16 in this study). In the present study, three factors are thought to influence the process of lactose electro-isomerization into lactulose in the electro-activation reactor. The electric current $\left(\mathrm{X}_{1}\right)$, the working temperature $\left(\mathrm{X}_{2}\right)$, and the reactor configuration $\left(\mathrm{X}_{3}\right)$. Two electric current intensities $(200,300 \mathrm{~mA})$, two working temperatures $\left(10,20^{\circ} \mathrm{C}\right)$, and two reactor configurations \# 1 (CEM) and \# 2 (AEM) are chosen for the model. The matrix $\mathrm{X}$ of the experiments is shown in Table 1. Except of column $\mathrm{X}_{0}$, every column has an equal number with plus and minus signs. Then, the sum of products of signs in any two columns is zero. All these properties are implied by the orthogonality of the contrasts used to estimate the main effects. 
Table 1. Algebraic signs for calculating effects in the $2^{3}$ designs according to Yates' ordering (Yates, 1937)

\begin{tabular}{ccccccccc}
\hline Experiences & $\mathrm{X}_{0}$ & $\mathrm{X}_{1}$ & $\mathrm{X}_{2}$ & $\mathrm{X}_{3}$ & $\mathrm{X}_{1} \mathrm{X}_{2}$ & $\mathrm{X}_{1} \mathrm{X}_{3}$ & $\mathrm{X}_{2} \mathrm{X}_{3}$ & $\mathrm{X}_{1} \mathrm{X}_{2} \mathrm{X}_{3}$ \\
\hline 1 & +1 & -1 & -1 & -1 & +1 & +1 & +1 & -1 \\
2 & +1 & +1 & -1 & -1 & -1 & -1 & +1 & +1 \\
3 & +1 & -1 & +1 & -1 & -1 & +1 & -1 & +1 \\
4 & +1 & +1 & +1 & -1 & +1 & -1 & -1 & -1 \\
5 & +1 & -1 & -1 & +1 & +1 & -1 & -1 & +1 \\
6 & +1 & +1 & -1 & +1 & -1 & +1 & -1 & -1 \\
7 & +1 & -1 & +1 & +1 & -1 & -1 & +1 & -1 \\
8 & +1 & +1 & +1 & +1 & +1 & +1 & +1 & +1 \\
\hline
\end{tabular}

The coefficients of the Equation (2) are determined by the method of the least means squares starting from the following condition (Equation 4):

$$
\varphi=\sum_{1=1}^{\mathrm{N}}\left(\mathrm{y}_{\mathrm{i}}-\hat{\mathrm{y}}\right)=\min
$$

A necessary condition for $\varphi$ will be minimized, the following equalities must be verified by the Equation 5:

Then,

$$
\frac{\partial \varphi}{\partial \mathrm{b}_{1}}=0, \frac{\partial \varphi}{\partial \mathrm{b}_{2}}=0, \frac{\partial \varphi}{\partial \mathrm{b}_{3}}=0
$$

$$
\begin{aligned}
& \sum_{i=1}^{N} 2\left[y_{i}-f\left(X_{i}, b_{0}, b_{1}, \ldots\right)\right] \frac{\partial f\left(X_{i}\right)}{\partial b_{0}}=0 \\
& \sum_{i=1}^{N} 2\left[y_{i}-f\left(X_{i}, b_{0}, b_{1}, \ldots\right)\right] \frac{\partial f\left(X_{i}\right)}{\partial b_{1}}=0
\end{aligned}
$$

Let introduce the statistical equipment of departure under independent variables matrix form, Equation 6

$$
[\mathrm{X}]=\left[\begin{array}{ccccc}
\mathrm{X}_{01} & \mathrm{X}_{11} & \mathrm{X}_{21} & \ldots & \mathrm{X}_{\mathrm{K} 1} \\
\mathrm{X}_{02} & \mathrm{X}_{12} & \mathrm{X}_{22} & \ldots & \mathrm{X}_{\mathrm{K} 2} \\
\cdot & \cdot & \cdot & \ldots & \cdot \\
\cdot & \cdot & \cdot & \ldots & \cdot \\
\cdot & \cdot & \cdot & \ldots & \cdot \\
\mathrm{X}_{0 \mathrm{~N}} & \mathrm{X}_{1 \mathrm{~N}} & \mathrm{X}_{2 \mathrm{~N}} & \ldots & \mathrm{X}_{\mathrm{KN}}
\end{array}\right]
$$

$\mathrm{Y}$ is the observations vector, Equation 7

$$
\mathrm{Y}=\left[\begin{array}{c}
\mathrm{y}_{1} \\
\mathrm{y}_{2} \\
\cdot \\
\cdot \\
\mathrm{y}_{\mathrm{N}}
\end{array}\right]
$$

The column matrix of coefficient is given in Equation 8 . 


$$
\mathrm{B}=\left[\begin{array}{c}
\mathrm{b}_{0} \\
\mathrm{~b}_{1} \\
\cdot \\
\cdot \\
\mathrm{b}_{\mathrm{k}}
\end{array}\right]
$$

The transposed matrix is given in Equation 9.

$$
[\mathrm{X}]^{\mathrm{T}}=\left[\begin{array}{cccc}
\mathrm{X}_{01} & \mathrm{X}_{02} & \ldots & \mathrm{X}_{0 \mathrm{~N}} \\
\mathrm{X}_{11} & \mathrm{X}_{12} & \ldots & \mathrm{X}_{1 \mathrm{~N}} \\
\cdot & \cdot & \ldots & \cdot \\
\cdot & \cdot & \ldots & \cdot \\
\cdot & \cdot & \ldots & \cdot \\
\mathrm{X}_{\mathrm{K} 1} & \mathrm{X}_{\mathrm{K} 2} & \ldots & \mathrm{X}_{\mathrm{KN}}
\end{array}\right]
$$

The equation system intended to determine coefficients is given in Equation 10.

$$
\left\{\begin{array}{l}
\mathrm{b}_{0} \sum_{\mathrm{i}=1}^{\mathrm{N}} \mathrm{X}_{0 \mathrm{i}}^{2}+\mathrm{b}_{1} \sum_{\mathrm{i}=1}^{\mathrm{N}} \mathrm{X}_{0 \mathrm{i}} \mathrm{X}_{1 \mathrm{i}}+\ldots+\mathrm{b}_{\mathrm{k}} \sum_{\mathrm{i}=1}^{\mathrm{N}} \mathrm{X}_{0 \mathrm{i}} \mathrm{X}_{\mathrm{Ki}}=\sum_{\mathrm{i}=1}^{\mathrm{N}} \mathrm{X}_{0 \mathrm{i}} \mathrm{y}_{\mathrm{i}} \\
\mathrm{b}_{0} \sum_{\mathrm{i}=1}^{\mathrm{N}} \mathrm{X}_{1 \mathrm{i}} \mathrm{X}_{0 \mathrm{i}}+\mathrm{b}_{1} \sum_{\mathrm{i}=1}^{\mathrm{N}} \mathrm{X}_{1 \mathrm{i}}^{2}+\ldots+\mathrm{b}_{\mathrm{k}} \sum_{\mathrm{i}=1}^{\mathrm{N}} \mathrm{X}_{1 \mathrm{i}} \mathrm{X}_{\mathrm{Ki}}=\sum_{\mathrm{i}=1}^{\mathrm{N}} \mathrm{X}_{1 \mathrm{i}} \mathrm{y}_{\mathrm{i}} \\
\mathrm{b}_{0} \sum_{\mathrm{i}=1}^{\mathrm{N}} \mathrm{X}_{\mathrm{Ki}} \mathrm{X}_{0 \mathrm{i}}+\mathrm{b}_{1} \sum_{\mathrm{i}=1}^{\mathrm{N}} \mathrm{X}_{\mathrm{Ki}} \mathrm{X}_{1 \mathrm{i}}+\ldots+\mathrm{b}_{\mathrm{k}} \sum_{\mathrm{i}=1}^{\mathrm{N}} \mathrm{X}_{\mathrm{Ki}}^{2}=\sum_{\mathrm{i}=1}^{\mathrm{N}} \mathrm{X}_{\mathrm{Ki}} \mathrm{y}_{\mathrm{i}}
\end{array}\right.
$$

Then, it can be written under matrix form, Equation 11, 12 and 13.

$$
\begin{aligned}
& {\left[\mathrm{X}^{\mathrm{T}} \mathrm{X}\right] \mathrm{B}=[\mathrm{X}]^{\mathrm{T}} \mathrm{Y}} \\
& {\left[\mathrm{X}^{\mathrm{T}} \cdot \mathrm{X}\right]=\left[\begin{array}{cccc}
\sum \mathrm{X}_{0 \mathrm{i}}^{2} & \sum \mathrm{X}_{0 \mathrm{i}} \mathrm{X}_{1 \mathrm{i}} & \cdots & \sum \mathrm{X}_{0 \mathrm{i}} \mathrm{X}_{\mathrm{ki}} \\
\sum \mathrm{X}_{\mathrm{li}} \mathrm{X}_{0 \mathrm{i}} & \sum \mathrm{X}_{\mathrm{li}}^{2} & \cdots & \sum \mathrm{X}_{\mathrm{li}} \mathrm{X}_{\mathrm{ki}} \\
\cdot & \cdot & \cdots & \cdot \\
\cdot & \cdot & \cdots & \cdot \\
\cdot & \cdot & \cdots & \cdot \\
\sum \mathrm{X}_{\mathrm{Ki}} \mathrm{X}_{0 \mathrm{i}} & \sum \mathrm{X}_{\mathrm{Ki}} \mathrm{X}_{1 \mathrm{i}} & \cdots & \sum \mathrm{X}_{\mathrm{Ki}}^{2}
\end{array}\right]} \\
& {\left[\mathrm{X}^{\mathrm{T}} \mathrm{Y}=\left[\begin{array}{c}
\sum \mathrm{X}_{0 \mathrm{i}} \mathrm{y}_{\mathrm{i}} \\
\sum \mathrm{X}_{\mathrm{li}} \mathrm{y}_{\mathrm{i}} \\
\cdots \\
\cdots \\
\sum \mathrm{X}_{\mathrm{Ki}} \mathrm{y}_{\mathrm{i}}
\end{array}\right]\right.}
\end{aligned}
$$

The coefficients vector solution is shown in Equation 14. 


$$
\mathrm{B}=\left[\mathrm{X}^{\mathrm{T}} \cdot \mathrm{X}\right]^{-1} \cdot[\mathrm{X}]^{\mathrm{T}} \cdot \mathrm{Y}
$$

For linear effects, the values of the coefficients are determined by the Equation 15 .

$$
\mathrm{b}_{\mathrm{j}}=\frac{1}{\mathrm{~N}} \sum_{i=1}^{N} \mathrm{X}_{\mathrm{ji}} \mathrm{y}_{\mathrm{i}}
$$

For the interaction effects, coefficient values are determined by Equations 16-17.

$$
\begin{gathered}
b_{j i}=\frac{1}{N} \sum_{\substack{i=1 \\
j \neq i}}^{N}\left(X_{i} X_{j}\right)_{i} y_{i} \\
b_{j i p}=\frac{1}{N} \sum_{\substack{i=1 \\
j \neq i \neq p}}^{N}\left(X_{i} X_{j} X_{p}\right)_{i} y_{i}
\end{gathered}
$$

In all cases, $\mathrm{j}=1 \ldots \mathrm{k} ; \mathrm{p}=1 \ldots \mathrm{k}$ and $\mathrm{j} \neq \mathrm{p}$

The results of the calculated coefficients are shown in the Table 2.

Table 2. Model coefficient values of lactose isomerisation in electro-activation reactor

\begin{tabular}{cccccccc}
\hline Constant term & \multicolumn{3}{c}{ Linear effects } & \multicolumn{5}{c}{ Interaction effects } \\
\hline $\mathrm{b}_{0}$ & $\mathrm{~b}_{1}$ & $\mathrm{~b}_{2}$ & $\mathrm{~b}_{3}$ & $\mathrm{~b}_{12}$ & $\mathrm{~b}_{13}$ & $\mathrm{~b}_{23}$ & $\mathrm{~b}_{123}$ \\
19.981 & -0.015 & -0.435 & 1.031 & -0.395 & -0.334 & -0.239 & -0.362 \\
\hline
\end{tabular}

\subsection{Analysis of the Regression Model}

The variance of the sample mean is given in Equation (18)

$$
\mathrm{s}_{\mathrm{i}}^{2}=\frac{\sum_{\mathrm{u}=1}^{\mathrm{N}}\left(\mathrm{y}_{\mathrm{iu}}-\overline{\mathrm{y}}_{\mathrm{i}}\right)^{2}}{\mathrm{~m}-1}
$$

Where $\mathrm{m}$ is the replicate number.

$$
\overline{\mathrm{y}}_{\mathrm{i}}=\frac{\sum_{\mathrm{u}=1}^{\mathrm{N}} \mathrm{y}_{\mathrm{iu}}}{\mathrm{m}}
$$

The variances which represent the experimental results are given on the Table 3.

Table 3. Survey variances values.

\begin{tabular}{llllllll}
\hline $\mathbf{S}_{\mathbf{1}}{ }^{2}$ & $\mathbf{S}_{\mathbf{2}}{ }^{2}$ & $\mathbf{S}_{\mathbf{3}}{ }^{2}$ & $\mathbf{S}_{\mathbf{4}}{ }^{2}$ & $\mathbf{S}_{\mathbf{5}}{ }^{2}$ & $\mathbf{S}_{\mathbf{6}}{ }^{2}$ & $\mathbf{S}_{7}{ }^{2}$ & $\mathbf{S}_{\mathbf{8}}{ }^{2}$ \\
\hline 0.106 & 0.127 & 0.096 & 0.090 & 0.106 & 0.123 & 0.106 & 0.090 \\
\hline
\end{tabular}

One supposes that $\mathrm{N}$ populations admit $\mathrm{s}_{1}{ }^{2}, \mathrm{~s}_{2}{ }^{2}, \mathrm{~s}_{3}{ }^{2} \ldots \mathrm{s}_{\mathrm{k}}{ }^{2}$ like variance (Montgomery, 1976). One tests:

$\mathrm{H}_{0}{ }^{\prime \prime} \mathrm{s}_{1}^{2}=\mathrm{s}_{2}^{2}=\ldots=\mathrm{s}_{\mathrm{k}}^{2} "$ Against $\mathrm{H}_{1}{ }^{\prime \prime} \exists \mathrm{i}$ and $\mathrm{i}^{\prime}, \mathrm{i} \neq \mathrm{i}^{\prime}$ such as $\mathrm{s}_{\mathrm{i}}^{2} \neq \mathrm{s}_{\mathrm{i}^{\prime}}^{2} "$

If all the numbers of degrees of freedom are equal between them:

$\mathrm{f}_{1}=\mathrm{f}_{2}=\ldots=\mathrm{f}_{\mathrm{k}}=\mathrm{m}-1$

One uses the Cochran's statistics defined by Equation 19. 


$$
\mathrm{G}_{\max }=\frac{\mathrm{s}_{\max }^{2}}{\sum_{\mathrm{i}=1}^{\mathrm{N}} \mathrm{s}_{\mathrm{i}}^{2}}
$$

$\mathrm{G}_{\max }=0.150$

Where

$\mathrm{s}_{\max }^{2}$ is the maximum value of the survey variance.

If $\mathrm{G}_{\max } \succ \mathrm{G}_{\alpha}(\mathrm{N}, \mathrm{m}-1)$ i.e $\mathrm{H} 0$ hypothesis rejected, else the variances are homogenous

Where

$\mathrm{G}_{\alpha}(\mathrm{N}, \mathrm{m}-1)$ is the value given in Cochran's table for the signification level of $\alpha$.

$\mathrm{G}_{0.05}(8,2)=0.6798$

Than $\mathrm{G}_{\max } \prec \mathrm{G}_{0.05}(8,2)$ i.e all variances are homogeneous.

If the variances are homogenous, then the equation 20 must be verified:

$$
\mathrm{M} \prec \mathrm{M}_{\mathrm{c}}\left(\alpha, \mathrm{f}_{\mathrm{i}}\right)
$$

Where

$M_{c}\left(\alpha, f_{i}\right)$ is the value given in Bartlett's table.

$f_{i}$ is the number of freedom, $i=1, \ldots N$

If $\mathrm{N}$ experiments are repeated $\mathrm{m}$ time, there will be then:

$\mathrm{f}_{1}=\mathrm{f}_{2}=\ldots=\mathrm{f}_{\mathrm{N}}=\mathrm{m}-1=2$

$\mathrm{f}=\sum_{\mathrm{i}=1}^{\mathrm{N}} \mathrm{f}_{\mathrm{i}}=24$

$\mathrm{M}=-\sum_{\mathrm{i}=1}^{\mathrm{N}} \mathrm{f}_{\mathrm{i}} \log \left[\frac{\mathrm{s}_{\mathrm{i}}^{2}}{\frac{1}{\mathrm{~N}} \sum_{\mathrm{i}=1}^{\mathrm{N}} \mathrm{s}_{\mathrm{i}}^{2}}\right]=0.101$

$\mathrm{M}_{\mathrm{c}}\left(\alpha, \mathrm{f}_{\mathrm{i}}\right) \approx \mathrm{C}_{\chi^{2}}(\alpha, \mathrm{N}-1)$

$\mathrm{C}=1+\frac{1}{3(\mathrm{~N}-1)}\left[\left(\sum_{\mathrm{i}=1}^{\mathrm{N}} \frac{1}{\mathrm{f}_{\mathrm{i}}}\right)-\frac{1}{\mathrm{f}}\right]=1.025$

$\chi^{2}(0.05,7)=2.17$

Then $\mathrm{M}_{\mathrm{c}}(0.05,2)=2.226$

One notices that $\mathrm{M}_{\mathrm{c}} \succ \mathrm{M}$. Bartlett test confirms Cochran test which affirmed that the variances are homogeneous.

The test of Student makes it possible to determine so among all the coefficients of the model, if exists no significant coefficients, which will be eliminated from the regression equation because their influence on the yield of lactulose is negligible. The calculation procedure consists in determining the variance of reproducibility which is estimated by that calculated in the center of experimental field, as given in Equation 21.

$$
\mathrm{S}_{\text {rep }}^{2}=\frac{\sum_{\mathrm{i}=1}^{\mathrm{N}} \mathrm{s}_{\mathrm{i}}^{2}}{\mathrm{~N}}
$$


Where

$\mathrm{y}_{\mathrm{i}}$ is the experimental response of lactulose yield at experience $\mathrm{i}$

Then $\mathrm{S}_{\text {rep }}^{2}=0.1055$

In order to identify no significant coefficients via Student test, one determines tj values for each coefficient, as given in Equation 22.

$$
\mathrm{t}_{\mathrm{j}}=\frac{\left|\mathrm{b}_{\mathrm{j}}\right|}{\mathrm{S}_{\mathrm{b}_{\mathrm{j}}}}
$$

Where

$\mathrm{S}_{\mathrm{b}_{\mathrm{j}}}$ is the mean quadratic variation, given in Equation 23.

$$
\mathrm{S}_{\mathrm{b}_{\mathrm{j}}}=\frac{\mathrm{S}_{\mathrm{rep}}}{\sqrt{\mathrm{m} * \mathrm{~N}}}
$$

$\mathrm{S}_{\mathrm{b}_{\mathrm{j}}}=0.066$

The results of the calculated coefficients are gathered in the Table 4.

Table 4. Calculated $t_{j}$ values for each model coefficient

\begin{tabular}{cccccccc}
\hline Constant term & \multicolumn{3}{c}{ Linear effects } & \multicolumn{5}{c}{ Interaction effects } \\
\hline $\mathrm{t}_{0}$ & $\mathrm{t}_{1}$ & $\mathrm{t}_{2}$ & $\mathrm{t}_{3}$ & $\mathrm{t}_{12}$ & $\mathrm{t}_{13}$ & $\mathrm{t}_{23}$ & $\mathrm{t}_{123}$ \\
302.746 & 0.227 & 6.591 & 15.619 & 5.985 & 5.063 & 3.624 & 5.492 \\
\hline
\end{tabular}

By using Student's table relative to a bilateral test, one reads the value of $t_{\alpha}(f)$ for the level of significance $=0.05$ and the degree of freedom number $\mathrm{f}=\mathrm{N}(\mathrm{m}-1)=16$, is $\mathrm{t}_{0.05}(16)=2.12$. The value of $\mathrm{t}_{1}$ is lower than the value of $\mathrm{t}_{0.05}$ (16) given in Student's table, one deduces whereas the corresponding coefficients are not significant.

The regression equation being without bias, one can thus carry out the test of Fischer for the significance of the regression (Goupy, 2005), Equation 24.

$$
\mathrm{F}_{\mathrm{c}}=\frac{\left(\sum_{\mathrm{i}=1}^{\mathrm{N}}\left(\hat{\mathrm{y}}_{\mathrm{i}}-\mathrm{y}_{\text {mean }}\right)^{2} / l-1\right)}{\left(\sum_{\mathrm{i}=1}^{\mathrm{N}}\left(\overline{\mathrm{y}}_{\mathrm{i}}-\hat{\mathrm{y}}_{\mathrm{i}}\right)^{2} / \mathrm{N}-l\right)}
$$

Then $F_{c}=249.629$

And $\mathrm{y}_{\text {mean }}=\frac{\sum_{\mathrm{i}=1}^{\mathrm{N}} \overline{\mathrm{y}}_{\mathrm{i}}}{\mathrm{N}}=20.22$

According to the Fisher's table, $\mathrm{F}_{0.95}(1-1, \mathrm{~N}-1)=\mathrm{F}_{0.95}(6,1)=234$. As this value being lower than that calculated $\mathrm{F}_{\mathrm{c}}$, the regression equation can be considered adequate and the equation is valid to $95 \%$, on one hand, it is without bias on the other hand.

Then, the regression equation is given in Equation 25. 


$$
\hat{y}=19.981-0.435 X_{2}+1.031 X_{3}-0.395 X_{1} X_{2}-0.334 X_{1} X_{3}-0.239 X_{2} X_{3}-0.360 X_{1} X_{2} X_{3}
$$

\subsection{Calculation of Determination Coefficient}

The determination coefficient value is given in Equation 26.

$$
R^{2}=\frac{\sum_{i=1}^{N}\left(\hat{y}_{i}-\bar{y}\right)^{2}}{\sum_{i=1}^{N}\left(y_{i}-\bar{y}\right)^{2}}
$$

$\mathrm{R}^{2}=0.98$

Then, the corrected coefficient is given in Equation 27.

$$
\overline{\mathrm{R}}^{2}=\mathrm{R}^{2}-\left(1-\mathrm{R}^{2}\right) \frac{1-1}{\mathrm{~N}-1}
$$

$\overline{\mathrm{R}}^{2}=0.96$

These values let us to confirm that the chosen regression equation can be considered as appropriate.

\subsection{Materials and Method and Experimental Validation}

\subsubsection{Chemicals}

Lactose was purchased from Baltimore Biological Laboratory, USA, CAS Number: 603643. Standards of lactulose, glucose, galactose and fructose were purchased from Sigma-Aldrich, Canada. Sodium sulfate $\left(\mathrm{Na}_{2} \mathrm{SO}_{4}\right)$ and calcium chloride $\left(\mathrm{CaCl}_{2} 2 \mathrm{H}_{2} \mathrm{O}\right)$ were purchased from Scientific Fisher, Canada, CAS Number: 051558 and 045891, respectively.

\subsubsection{Membranes}

New and non-prepared for direct use anion (AM-40) and cation (CM-40) exchange membranes were purchased from the Publicly Traded Company Schekina-Azot (Shchekina, Russian Federation). A hydrophilic polyether-sulfone nanofiltration membrane N30F (Basel, Switzerland) was used.

\subsubsection{Ion Exchange Membranes Pre-Treatment}

Before the use of the ion exchange membranes in the electro-activation reactor, a pre-treatment was necessary and conducted as specified by the manufacturer: Firstly, the membrane surface was cleaned by $95 \%$-ethanol. After that, they were kept for $24 \mathrm{~h}$ in a saturated $\mathrm{NaCl}$ solution $(320 \mathrm{~g} / \mathrm{L})$. Then, they were washed with distilled water and kept again in a $160 \mathrm{~g} / \mathrm{L} \mathrm{NaCl}$ solution for another $24 \mathrm{~h}$. After, they were again washed with distilled water and kept in an $80 \mathrm{~g} / \mathrm{L} \mathrm{NaCl}$ solution for $24 \mathrm{~h}$. Finally, the membranes were transferred into a diluted $\mathrm{NaCl}$ solution $(40 \mathrm{~g} / \mathrm{L})$ until use.

\subsubsection{Electro-Activation Reactor Design}

The used electro-activation reactor was composed of three compartments (anodic, central and cathodic). The cathodic compartment was the one dedicated to the electro-isomerization reaction and was filled with $60 \mathrm{~mL}$ of lactose solution $(10 \% \mathrm{w} / \mathrm{v})$ and $0.05 \mathrm{M} / \mathrm{L}$ of calcium chloride hydrate $\left(\mathrm{CaCl}_{2} \cdot 2 \mathrm{H}_{2} \mathrm{O}\right)$. The calcium chloride was used in order to ensure the passage of electric current in the lactose solution at the moment when the electro-activation process was run. The anodic and central compartments were filled with similar electrolyte composed of sodium sulfate $\left(\mathrm{Na}_{2} \mathrm{SO}_{4}\right)$ at $0.3 \mathrm{M} / \mathrm{L}$ concentration. Dependently of the reactor configuration, the central compartment was separated from the cathodic one by cation, anion exchange membrane or nanofiltration membrane. Two dimensionally stable electrodes were installed in the anodic and cathodic compartments. The anodic electrode was made of Ruthenium-Iridium coated titanium which is highly resistant to corrosion. A food grade Stainless-304 electrode was used in the cathodic side. Both the electrodes were connected to a direct current electric generator (Gw INSTECK SPS 3610 EL 894065). In this study, sub-ambient temperatures were used. To ensure these conditions, the electro-activation reactor was directly placed in a refrigerated bath under circulating mode (Fisher Scientific, ISOTEMP 1016S, USA). Finally, a mixing device (Cafrano, Canada, $\mathrm{N}^{\circ}$ 12865) was placed in the cathodic compartment to ensure homogeneity of the solution throughout the electro-activation process. Samples from the cathodic compartment were collected at 2, 10 and 30 min after the process was started. The conductivity $(\lambda)$ and the $\mathrm{pH}$ of the solution in the cathodic compartment were 
measured by using conductivity meter (Model SR 601 C SympHony, VWR Scientific Products, USA) and pH meter (Model OAKTON pH 700, EUTECH Instruments SN 929391).

\subsubsection{Reactor Configuration}

The electro-isomerization of lactose into lactulose was studied under 3 different reactor configurations as follows:

Config. 1: Anode / $0.3 \mathrm{M} \mathrm{Na}_{2} \mathrm{SO}_{4}$ solution / AEM (MA-40) / $0.3 \mathrm{M} \mathrm{Na}_{2} \mathrm{SO}_{4}$ solution / CEM (MC-40) / 10\% (w/v) Lactose / Cathode.

Config. 2: Anode / $0.3 \mathrm{M} \mathrm{Na}_{2} \mathrm{SO}_{4}$ solution / $\mathrm{AEM}$ (MA-40) / $0.3 \mathrm{M} \mathrm{Na}_{2} \mathrm{SO}_{4}$ solution / NFM (NF30) (nanofiltration membrane) / 10\% (w/v) Lactose / Cathode.

Config. 3: Anode / $0.3 \mathrm{M} \mathrm{Na}_{2} \mathrm{SO}_{4}$ solution / CEM (MA-40) / $0.3 \mathrm{M} \mathrm{Na}_{2} \mathrm{SO}_{4}$ solution / AEM (MA-40) / 10\% (w/v) Lactose / Cathode.

\subsubsection{Sugars HPLC Analyses}

The collected samples were analyzed by high performance liquid chromatography which was performed by an analytical HPLC system model 715 Alliance Waters (Milford, MA, USA) with a Refractive Index detector (Waters, Model 410). HPLC grade water degassed by ultrasound was used as the mobile phase. The analysis was carried out by using a Sugar-Pack column of 300 x $6.5 \mathrm{~mm}$ (Waters, Milford, MA, USA). HPLC analyses were carried out under an operating temperature of $85^{\circ} \mathrm{C}$ at a flow rate of $0.5 \mathrm{ml} . \mathrm{min}^{-1}$. Introduction of samples into the HPLC system was via an injection valve fitted with a $10 \mu \mathrm{l}$ injection loop. The run time was set at $30 \mathrm{~min}$ per sample.

\subsection{Statistical Analysis}

The process of lactose isomerization into lactulose by electro-activation was studied on the basis of a full factorial experimental design. Each measure was carried out in a triplicate and mean values \pm STD were calculated and used for the comparisons between the different treatments at $95 \%$ confidence level with a protected LSD test. Detailed analysis of the variance (ANOVA) was performed by means of SAS software (Version 9.1, SAS Institute, Cary, NC, USA). A decomposition of the ANOVA was also used to ensure the validity of the significance of each individual independent variable. Maple software (Version 14, Maplesoft, Waterloo Maple Inc, ON, Canada) was used for the process optimization.

\section{Results and Discussion}

\subsection{Model Effectiveness and Validation by Experimentation Layout}

The effectiveness is an indicator of the redundancy of an experimental design. It is defined by:

$$
\mathrm{E}=\frac{\text { Model coeffiecient Number }}{\text { Experiment Number }}=\frac{7}{8}=87.5 \%
$$

The Table 5 gives the comparison of lactulose yield results obtained by experiments and those given by the regression equation of second order. One notices that the maximum deviation between the lactulose yield given by the regression equation and that given by each experiment do not reach $1.4 \%$, which shows that the regression equation simulate perfectly the experiment.

Table 5. Calculation values of relative error

\begin{tabular}{cccc}
\hline Experiments & y \% & $\hat{\mathrm{y}} \%$ & Absolute relative errors $(\%)$ \\
\hline 1 & 19.033 & 18.779 & 1.333 \\
2 & 19.736 & 19.512 & 1.133 \\
3 & 18.706 & 18.452 & 1.356 \\
4 & 19.280 & 19.056 & 1.160 \\
5 & 21.516 & 21.262 & 1.179 \\
6 & 22.333 & 22.109 & 1.001 \\
7 & 21.683 & 21.429 & 1.170 \\
8 & 19.470 & 19.246 & 1.149 \\
\hline
\end{tabular}




\subsection{Effect of the Operating Parameters}

The effect of $\left(\mathrm{X}_{2}\right)$ corresponds to the working temperature. It has a negative effect on the lactulose production. The temperature increasing involves the lactose degradation into by products. The effect of the $\left(\mathrm{X}_{3}\right)$ parameter corresponds to the reactor configuration. It has a negative positive action on the lactulose production. By using the reactor configuration 1 (CEM), the lactulose yield is more important than the AEM using. To study this interaction in the absolute, it becomes to remove the influence of effect $\left(\mathrm{X}_{3}\right)$. The choice of the experiments allows it. Two experiments reply to this condition, Table 6. By summoning the results of these two experiments, the effect $\mathrm{X}_{3}$ and the interaction effects $\left(\mathrm{X}_{1}-\mathrm{X}_{3}, \mathrm{X}_{2}-\mathrm{X}_{3}, \mathrm{X}_{1}-\mathrm{X}_{2}-\mathrm{X}_{3}\right)$ cancel themselves. Thus one can isolate the only action from effect $X_{1}$ and $X_{2}$ (Figure 1a).

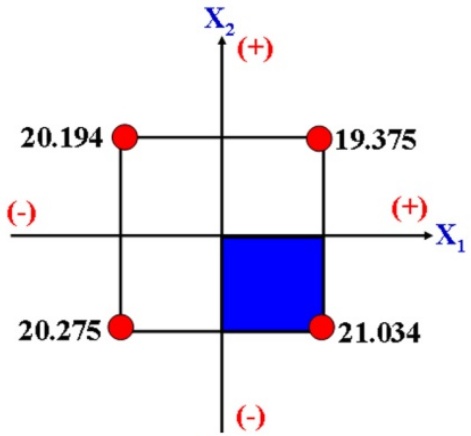

(a)

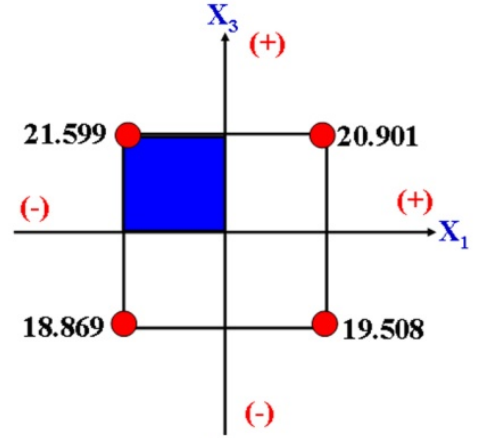

(b)

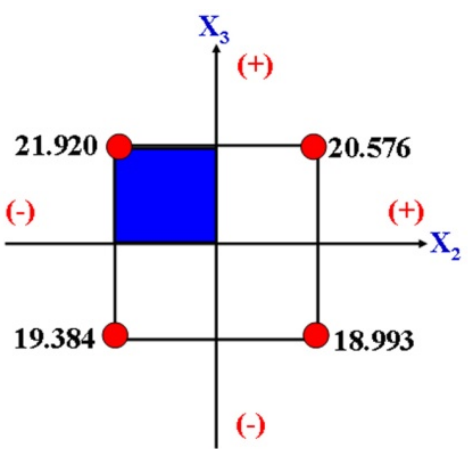

(c)

Figure 1. Diagram of interactions: (a) $\mathrm{X}_{1}-\mathrm{X}_{2}$, (b) $\mathrm{X}_{1}-\mathrm{X}_{3}$ and (c) $\mathrm{X}_{2}-\mathrm{X}_{3}$

On the Figure 1a, one notices that the high lactulose yield $(21.034 \%)$ is produced at high electrical current $(\mathrm{I}=$ $300 \mathrm{~mA})$ and at low working temperature $\left(\mathrm{T}=10^{\circ} \mathrm{C}\right)$. However, the low lactulose yield is produced at high electrical current but at high working temperature.

Table 6. Experiences which allow the interaction $\mathrm{X}_{1}-\mathrm{X}_{2}$ without $\mathrm{X}_{3}$

\begin{tabular}{lllll}
\hline Experiences & $\mathrm{X} 1$ & $\mathrm{X} 2$ & $\mathrm{X} 3$ & $\mathrm{Y}_{\mathrm{i}}$ \\
\hline 6 & +1 & +1 & -1 & 19.280 \\
8 & +1 & +1 & +1 & 19.470 \\
\hline
\end{tabular}

To study this interaction, it becomes to remove the influence of effect $\left(\mathrm{X}_{2}\right)$. Two experiments reply to this condition, Table 7. By summoning the results of these two experiments, the effect $X_{2}$ and the interaction effects $\left(\mathrm{X}_{1}-\mathrm{X}_{2}, \mathrm{X}_{2}-\mathrm{X}_{3}, \mathrm{X}_{1}-\mathrm{X}_{2}-\mathrm{X}_{3}\right)$ cancel themselves. Thus one can isolate the only action from effect $\mathrm{X}_{1}$ and $\mathrm{X}_{3}$ (Figure 1b) which shows the interaction between $X_{1}$ (electric current) and $X_{3}$ (reactor configuration). One notices that the high lactulose yield $(21.599 \%)$ is produced at low electrical value $(\mathrm{I}=200 \mathrm{~mA})$ by using the reactor configuration 1 (by using the cation exchange membrane between the central and cathodic compartment). The low lactulose yield is obtained at low electrical current by using the reactor configuration 2 (anion exchange membrane is used to separate the central and cathodic compartment).

Table 7. Experiences which allow the interaction $X_{1}-X_{3}$ without $X_{2}$

\begin{tabular}{lllll}
\hline Experiences & $\mathbf{X 1}$ & $\mathbf{X 2}$ & $\mathbf{X 3}$ & $\mathbf{Y}_{\mathbf{i}}$ \\
\hline $\mathbf{6}$ & +1 & -1 & +1 & 22.333 \\
$\mathbf{8}$ & +1 & +1 & +1 & 19.470 \\
\hline
\end{tabular}

To study this interaction in the absolute, it becomes to remove the influence of effect $\left(\mathrm{X}_{1}\right)$. The choice of the experiments allows it. Two experiments reply to this condition, Table 8. By summoning the results of these two 
experiments, effect $X_{1}$ and the interaction effects $\left(X_{1}-X_{2}, X_{2}-X_{3}, X_{1}-X_{2}-X_{3}\right)$ cancel themselves. Thus one can isolate the only action from effect $X_{1}$ and $X_{3}$ (Figure 1c) which shows the interaction between $X_{2}$ (working temperature) and $\mathrm{X}_{3}$ (reactor configuration). It shows that the high lactulose yield (21.92\%) is produced when the cation exchange membrane separates the central and the cathodic compartment (reactor configuration 1). However, the low lactulose yield is produced at high working temperature $\left(20{ }^{\circ} \mathrm{C}\right)$ by using the reactor configuration 2 (anion exchange membrane used to separate the central and cathodic compartment).

Table 8. Experiences which allow the interaction $\mathrm{X}_{2}-\mathrm{X}_{3}$ without $\mathrm{X}_{1}$

\begin{tabular}{lllll}
\hline Experiences & $\mathbf{X 1}$ & $\mathbf{X 2}$ & $\mathbf{X 3}$ & $\mathbf{Y}_{\mathbf{i}}$ \\
\hline $\mathbf{7}$ & -1 & +1 & +1 & 21.683 \\
$\mathbf{8}$ & +1 & +1 & +1 & 19.470 \\
\hline
\end{tabular}

\subsection{Process Optimization}

One uses the regression equation, which postulated to represent the experiments, to calculate the optimal values of all parameters which can allow giving a maximal lactulose yield. For this, one must resolve the below equation system (Equation 28) by deriving the predictive equation at each variable $\mathrm{X}_{1}, \mathrm{X}_{2}$ and $\mathrm{X}_{3}$.

$$
\left\{\begin{array}{l}
\frac{\partial \hat{y}}{\partial X_{1}}=-0.395 X_{2}-0.334 X_{3}-0.362 X_{2} X_{3}=0 \\
\frac{\partial \hat{y}}{\partial X_{2}}=-0.015-0.395 X_{1}-0.239 X_{3}-0.362 X_{1} X_{3}=0 \\
\frac{\partial \hat{y}}{\partial X_{3}}=1.030-0.334 X_{1}-0.239 X_{2}-0.362 X_{1} X_{2}=0
\end{array}\right.
$$

By using Maple ${ }^{\circledR}$ v.14 software, the solution for the Equation (28) is given below.

$$
\left\{\begin{array} { l } 
{ \mathrm { X } _ { 1 } = 0 . 8 6 6 } \\
{ \mathrm { X } _ { 2 } = - 0 . 6 4 6 } \\
{ \mathrm { X } _ { 3 } = 1 . 3 4 0 5 }
\end{array} \Rightarrow \left\{\begin{array}{l}
\mathrm{I} \approx 293.3 \mathrm{~mA} \\
\mathrm{~T} \approx 15{ }^{\circ} \mathrm{C} \\
\text { Reactor configuration }=\mathrm{CEM}
\end{array}\right.\right.
$$

One notices that $\mathrm{X}_{3}=1.34$. However, this value is not including in the interval $[-1,+1]$. For this reason, one kept the value which is closer to it, $X_{3}=+1$. The theoretical lactulose yield obtained by replacing the optimal variable values in the applied model is $22 \%$. In order to confirm the existence of optimal yield, Figure 2 shows the response surface by plotting the lactulose yield (by using Maple $^{\circledR}$ v. 14.0) in the plan $X_{1}$ (electrical current) and $\mathrm{X}_{3}$ (reactor configuration), by fixing the variable $\mathrm{X}_{2}=-0.646$ (working temperature). The saddle form of this surface suggests that there is a maximum lactulose yield which is given by the point top coordinate. 


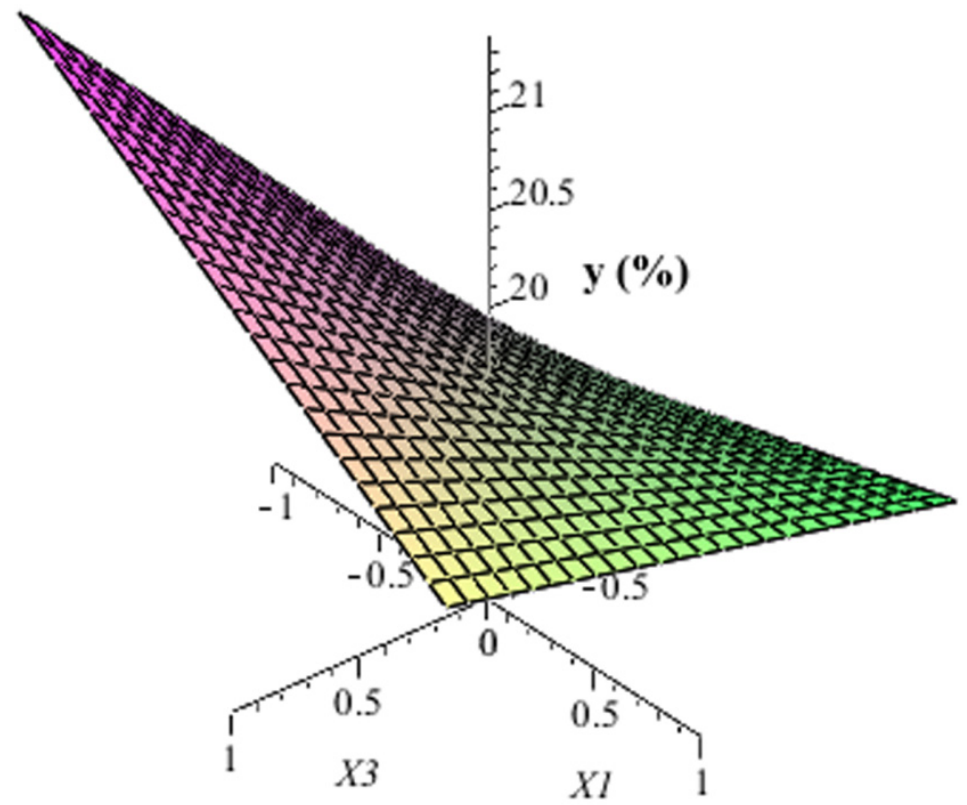

Figure 2. Response surface at $\mathrm{X}_{2}=-0.646\left(\right.$ Temperature, $\left.\mathrm{T}=15^{\circ} \mathrm{C}\right)$

\subsection{Iso-Response Curves}

The main objective of this work is to obtain a high lactulose yield by isomerisation of lactose in electroactivated reactor. Consequently, one finds the area of the study domain where this condition is observed. Therefore, the layout of the two level iso-responses of the three studied factors (electric current, temperature and reactor configuration) makes it possible both to predict the maximum value of the lactulose yield and to visualize the displacement of the delimiting optimum zone according to the operating conditions (Figures 3-5). The model is exploited in Figure 3 to highlight the dependence between the working temperature $\left(\mathrm{X}_{2}\right)$ and the reactor configuration $\left(\mathrm{X}_{3}\right)$, that while varying the electrical current $\left(\mathrm{X}_{1}=200 \mathrm{~mA}\right.$ and $\left.300 \mathrm{~mA}\right)$. The curves $(\mathrm{a}$ and $\mathrm{b})$ show both that the high lactulose yield is obtained while one chooses the reactor configuration $1\left(\mathrm{X}_{3}=+1\right)$ and the low temperatures values.

The models used in Figures 3 (a, b) are given in Equation (29-30) respectively.

$$
\begin{gathered}
\hat{y}_{\left(X_{1}=+1\right)}=19.981-0.830 X_{2}+0.697 X_{3}-0.599 X_{2} X_{3} \\
\hat{y}_{\left(X_{1}=-1\right)}=19.981-0.04 X_{2}+1.365 X_{3}+0.121 X_{2} X_{3}
\end{gathered}
$$




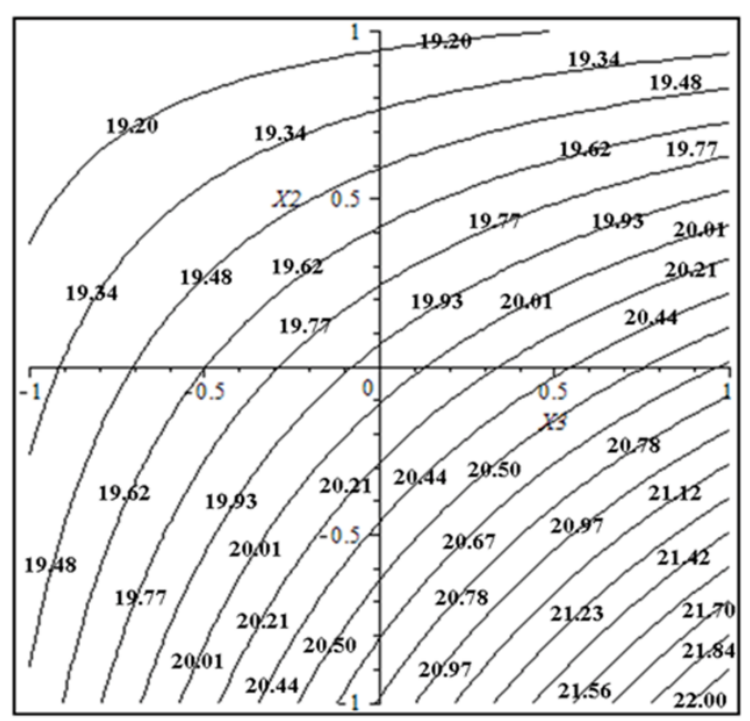

(a)

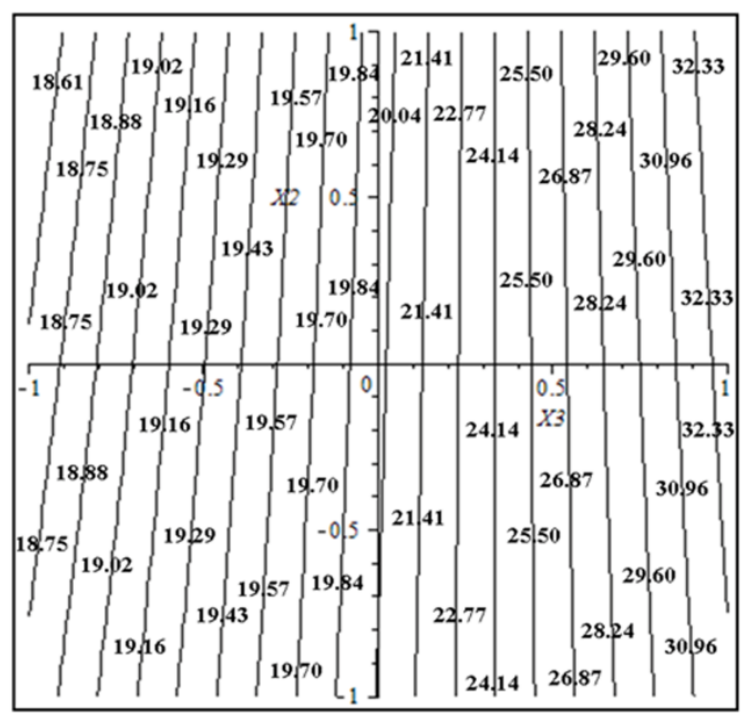

(b)

Figure 3. Iso-response curve at different level of $X_{1}$ : (a) $X_{1}=+1$, (b) $X_{1}=-1$

Figure 4 shows the highlight dependence between the electric current $\left(X_{1}\right)$ and the reactor configuration $\left(X_{3}\right)$, that while varying the working temperature $\left(\mathrm{X}_{2}=10^{\circ} \mathrm{C}\right.$ and $\left.20^{\circ} \mathrm{C}\right)$. The curves (a and b) show both that the high lactulose yield is obtained while one chooses the reactor configuration $1\left(\mathrm{X}_{3}=+1\right)$ and the low temperatures values. Figures $4(\mathrm{a}, \mathrm{b})$ are obtained by using the models given in equation (31-32) respectively.

$$
\begin{gathered}
\hat{\mathrm{y}}_{\left(\mathrm{X}_{2}=+1\right)}=19.546-0.395 \mathrm{X}_{1}+0.792 \mathrm{X}_{3}-0.694 \mathrm{X}_{1} \mathrm{X}_{3} \\
\hat{\mathrm{y}}_{\left(\mathrm{X}_{2}=-1\right)}=20.416+0.395 \mathrm{X}_{1}+1.270 \mathrm{X}_{3}+0.026 \mathrm{X}_{2} \mathrm{X}_{3}
\end{gathered}
$$

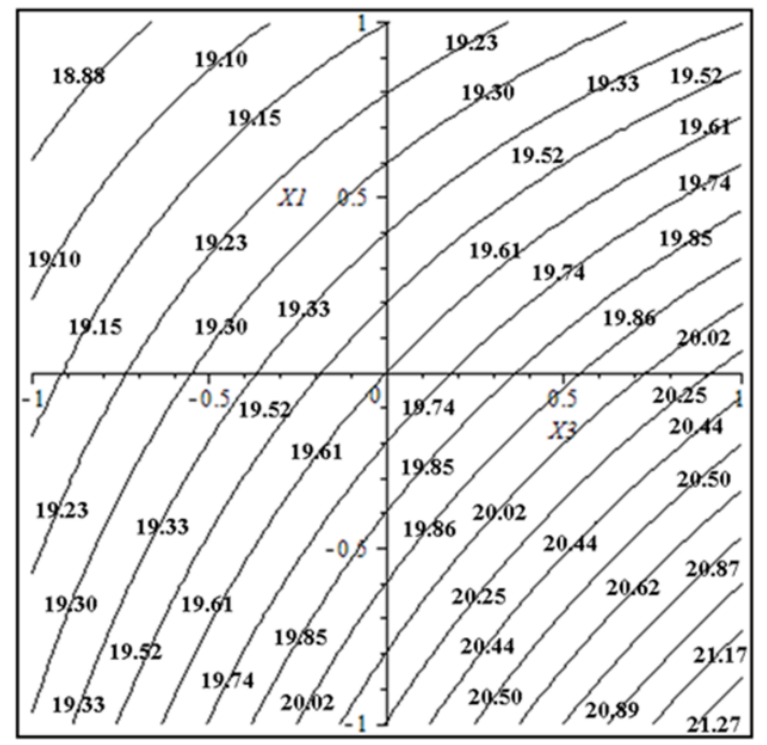

(a)

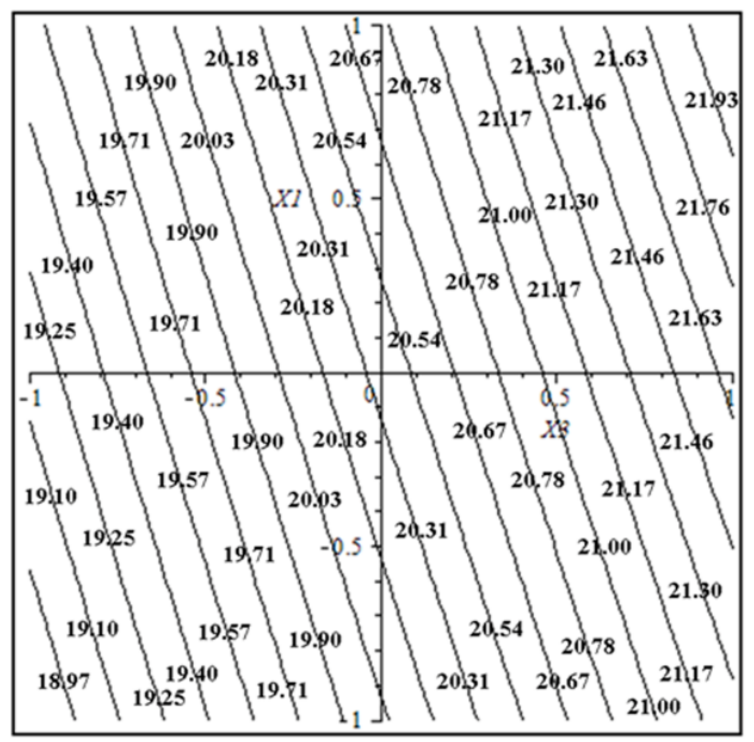

(b)

Figure 4. Iso-response curve at different level of $X_{2}$ : (a) $X_{2}=+1$, (b) $X_{2}=-1$ 
Figure 5 shows the dependence between the electric current $\left(\mathrm{X}_{1}\right)$ and the working temperature $\left(\mathrm{X}_{2}\right)$, that while varying the reactor configuration $\left(\mathrm{X}_{3}=+1\right.$ and -1$)$. The curves $(\mathrm{a}$ and $\mathrm{b}$ ) show both that the high lactulose yield is obtained while one chooses the high electrical current $\left(\mathrm{X}_{1}=+1\right)$ and the low temperatures values. Figures 5 (a and $\mathrm{b}$ ) are obtained by using the models given in equation (33-34) respectively.

$$
\begin{aligned}
& \hat{y}_{\left(X_{3}=+1\right)}=21.012-0.334 X_{1}-0.674 X_{2}-0.755 X_{1} X_{2} \\
& \hat{y}_{\left(X_{3}=-1\right)}=18.95+0.334 X_{1}-0.196 X_{2}-0.035 X_{1} X_{2}
\end{aligned}
$$

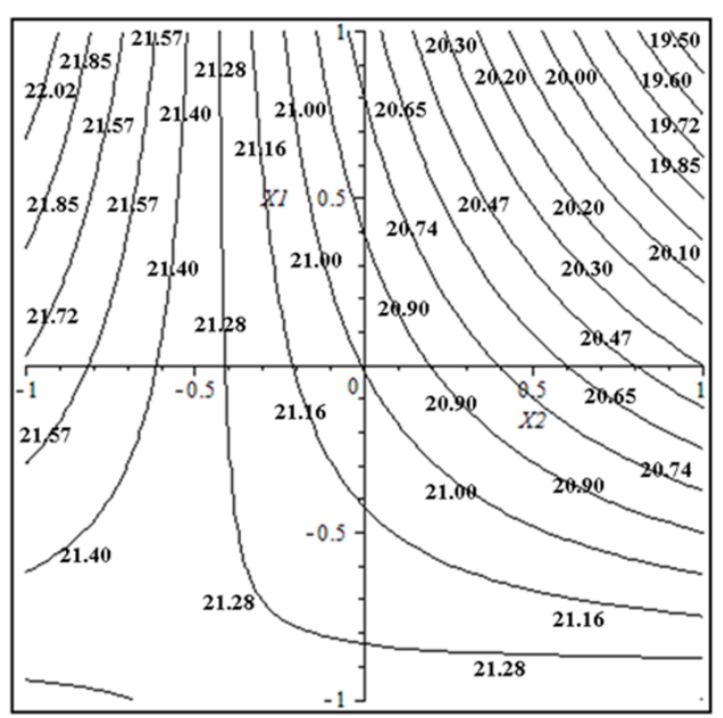

(a)

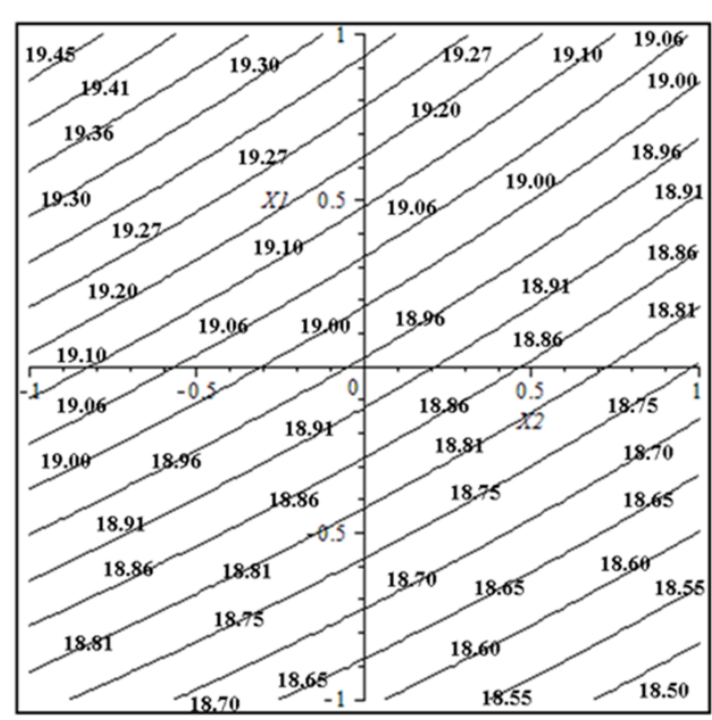

(b)

Figure 5. Iso-response curve at different level of $\mathrm{X}_{3}$ : (a) $\mathrm{X}_{3}=+1$, (b) $\mathrm{X}_{3}=-1$

The iso-response curves (Figures 3-5) assure well that the study areas which optimize the lactulose production yield contains all the maximum values which are generated by the factor interaction study, such as $20.19 \%\left(\mathrm{X}_{1}\right.$, $\left.\mathrm{X}_{2}\right) ; 21.599 \%\left(\mathrm{X}_{1}, \mathrm{X}_{3}\right)$ and $21.92 \%\left(\mathrm{X}_{2}, \mathrm{X}_{3}\right)$. The obtained experimental result for the process validation of the used model are summarized in the Figures 6-7. As it can be seen, lactulose production following lactose electro-isomerization is mainly governed by the current density. However, the end product quality (purity) is influenced by other process parameters such as the working temperature. 


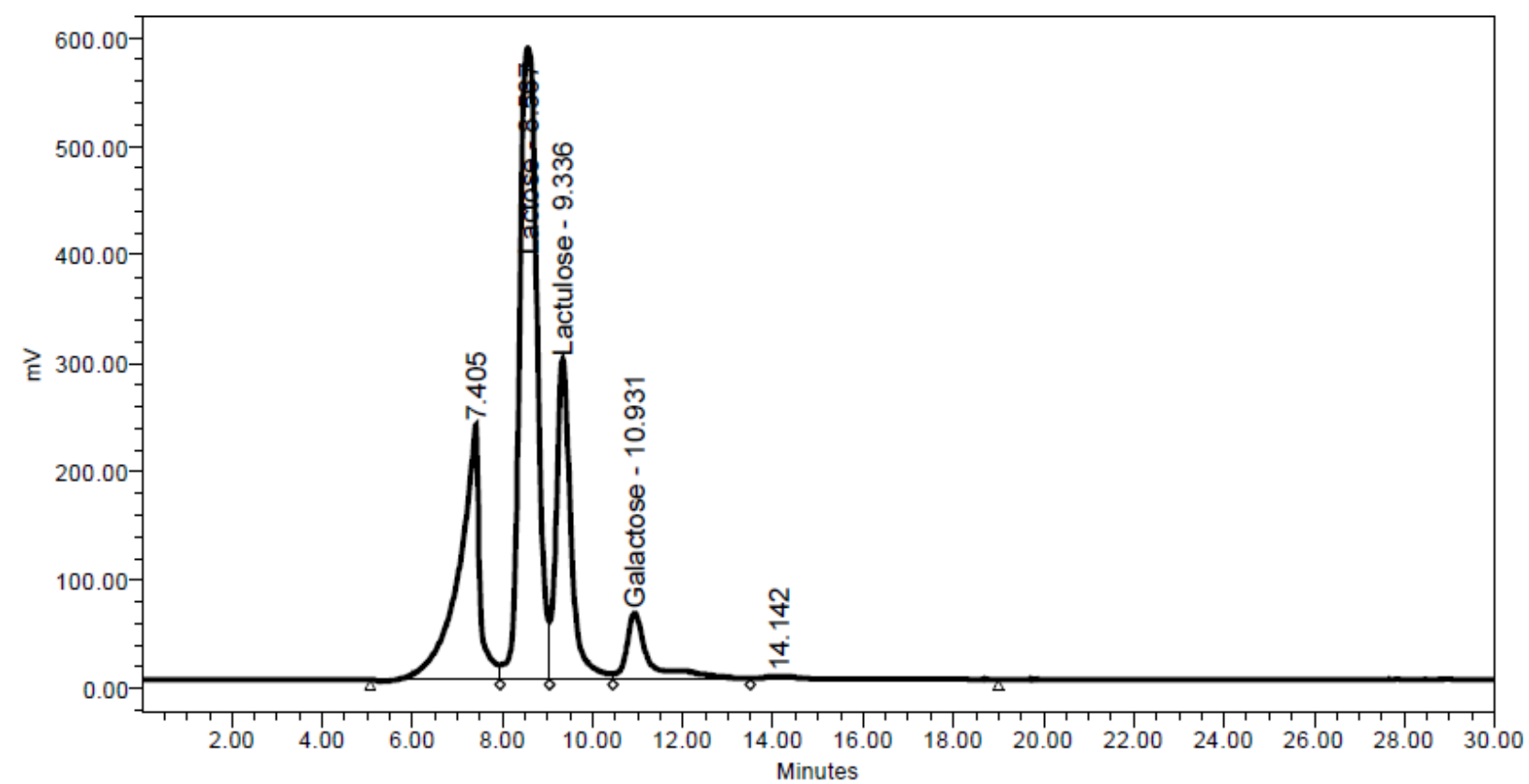

\begin{tabular}{|r|l|r|r|r|r|}
\hline \hline & Peak Name & RT & Area & \% Area & Height \\
\hline 1 & & 7.405 & 7523588 & 23.22 & 236937 \\
\hline 2 & Lactose & 8.567 & 15839064 & 48.87 & 582901 \\
\hline 3 & Lactulose & 9.336 & 6663833 & 20.56 & 295232 \\
\hline 4 & Glucose & 9.851 & & & \\
\hline 5 & Galactose & 10.931 & 2202955 & 6.80 & 61206 \\
\hline 6 & Fructose & 11.925 & & & \\
\hline
\end{tabular}

Figure 6. Evolution of lactulose conversion as a function of isomerisation time at different experimental parameters. (a) Configuration $2, \mathrm{~T}=10^{\circ} \mathrm{C}$; (b) $\mathrm{I}=200 \mathrm{~mA}, \mathrm{~T}=10^{\circ} \mathrm{C}$, (c) Configuration $2, \mathrm{I}=200 \mathrm{~mA}$ 
(a)

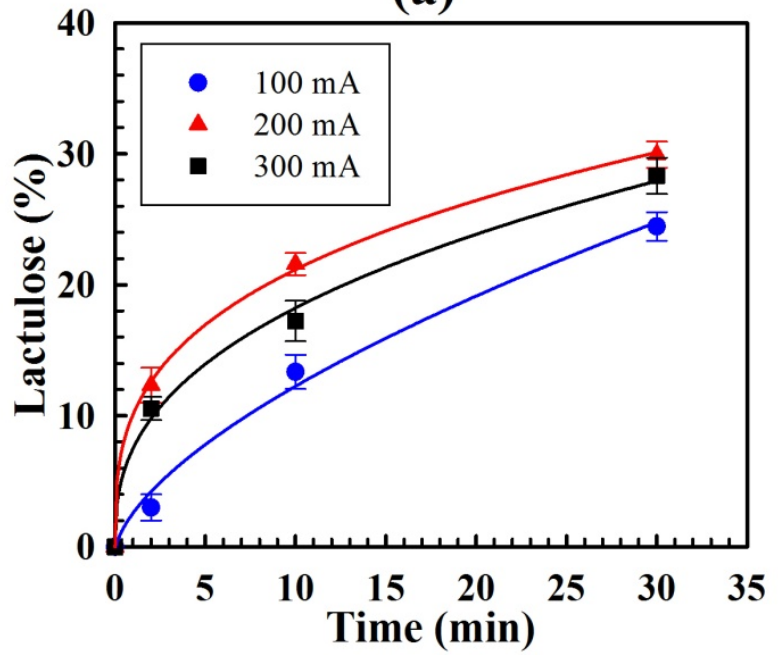

(b)

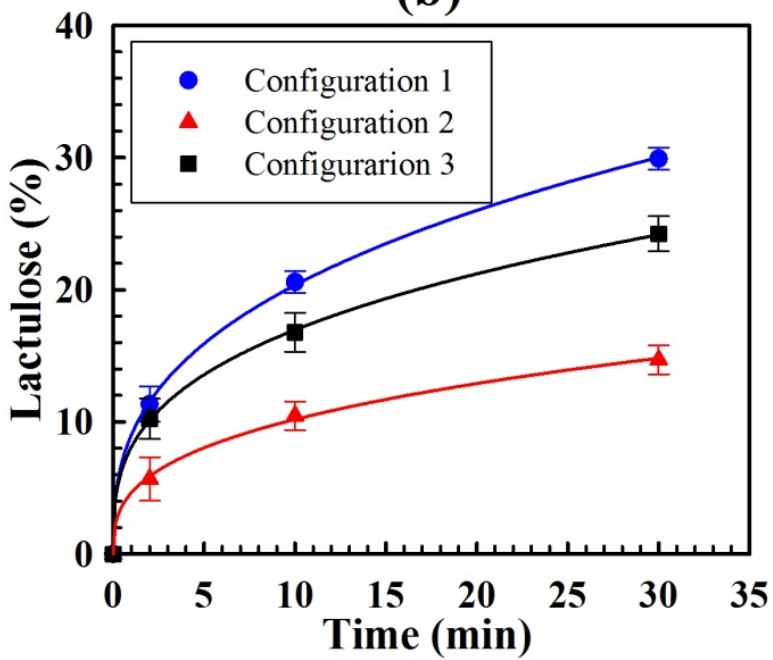

(c)

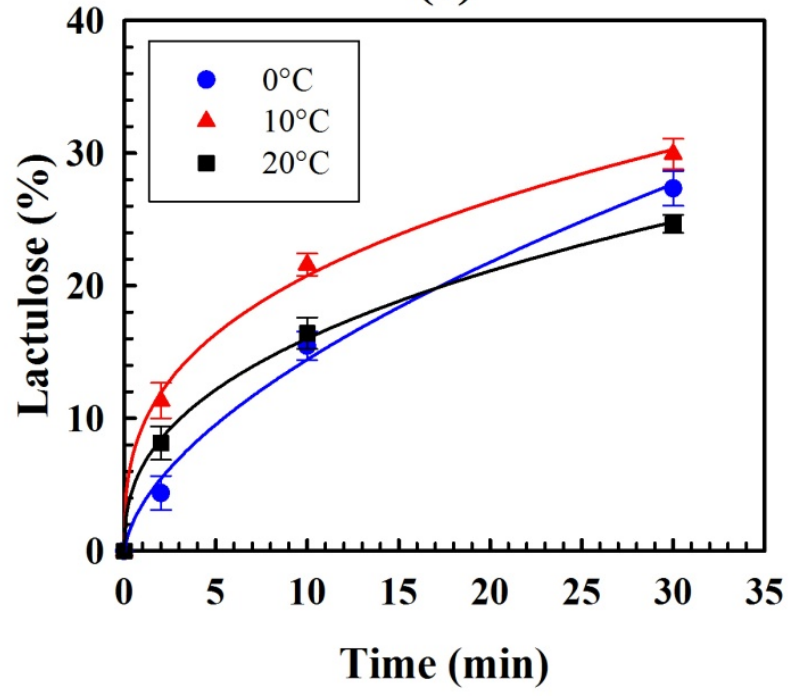

Figure 7. Evolution of lactulose produced as a function of isomerisation time at different experimental parameters. (a) Configuration $2, \mathrm{~T}=10^{\circ} \mathrm{C}$; (b) $\mathrm{I}=200 \mathrm{~mA}, \mathrm{~T}=10^{\circ} \mathrm{C}$, (c) Configuration $2, \mathrm{I}=200 \mathrm{~mA}$

\section{Conclusion}

In this work, lactulose was produced in an electro-activation reactor. Process parameters such as the electric current intensity $\mathrm{X}_{1}(200,300 \mathrm{~mA})$; working temperature, $\mathrm{X}_{2}\left(10-20{ }^{\circ} \mathrm{C}\right)$; reactor configuration, $\mathrm{X}_{3}(1(\mathrm{CEM}), 2$ (AEM)) were considered as the principal factors affecting the isomerization of lactose into lactulose by using the electro-activation process. A regression model which links the lactulose yield with the experimental parameters was developed in this work. The analysis of the variance (ANOVA) of the experimental data showed a high correlation coefficient $\mathrm{R}^{2}(0.98)$ and a low root mean square error (1.4\%) values indicating the good predictive of the model. Variance Homogeneous test, Cochran's test, Bartelett's test, Student's test, Fisher's test and Significant Regression test are applied to assure the validation and the effectiveness of the regression postulated model. The using full factorial experimental design $2^{3}$ allowed the selection of the optimal experimental conditions to generate $\mathrm{a} \approx 30 \%$ isomerization yield of the initial of lactose to free lactulose with minimal galactose formation. The following optimal experimental conditions were: electric current intensity I $\approx 300 \mathrm{~mA}$; working temperature, $\mathrm{T}=15^{\circ} \mathrm{C}$ (sub-ambient) and reactor configuration 1 (Config. 1) in which a cation exchange membrane was used to separate the cathodic compartment from the central section. This configuration is the most efficient since it allows keeping high reactivity of the isomerization medium. 


\section{References}

Aït Aissa, A., \& Aïder, M. (2013). Lactose isomerization into lactulose in an electro activation reactor and high-performance liquid chromatography (HPLC) monitoring of the process. Journal of Food Engineering 119, 115-124. http://dx.doi.org/10.1016/j.jfoodeng.2013.05.011

Damyanov, G., \& Germanova-Krasteva, D. (2012). Textile Processes: Quality control and design of experiments. Momentum Press, U.S.A. http://dx.doi.org/10.5643/9781606503898

Eriksson, L., Johansson, E., Kettaneh-Wold, N., Wikström C., \& Wold, S. (2008). Design of experiments: principles and applications. MKS Umetrics AB, Umea.

Goupy, J. (2005). Pratiquer les plans d'expériences (Dunod ed.). Paris.

Kozempel, M., \& Kurantz, M. (1994). A continuous reactor system for production of lactulose. Journal of Chemical Technology and Biotechnology, 59, 265-269. http://dx.doi.org/10.1002/jctb.280590309

Montgomery, D. C. (1976). Design and analysis of experiments (Wiley ed.). USA.

Paseephol, T., Darryl, M., Small, D. M., \& Sherkat, F. (2008). Lactulose production from milk concentration permeate using calcium carbonate-based catalysts. Food Chemistry, 111(1), $283-290$. http://dx.doi.org/10.1016/j.foodchem.2008.03.051

Siomina, I., \& Ahlinder, S. (2008). Lean optimization using supersaturated experimental design, Applied Numerical Mathematics, 58, 1-15. http://dx.doi.org/10.1016/j.apnum.2006.10.007

Tagushi, G., Tagushi, S., \& Chowdhury, S. (1999). Robust Engineering. U.S.A: McGraw-Hill.

Wu, C. F., \& Hamada, M. (2000). Experiments: Planning, Analysis, and Parameter Design Optimization. New York, Wiley.

Yates, F. (1937). The design and analysis of factorial experiments (Imperial Bureau of Soil Science ed.). England.

Zhang, X. D. (2011). Optimal high-throughput screening. Cambridge. http://dx.doi.org/10.1017/CBO9780511973888

\section{Copyrights}

Copyright for this article is retained by the author(s), with first publication rights granted to the journal.

This is an open-access article distributed under the terms and conditions of the Creative Commons Attribution license (http://creativecommons.org/licenses/by/3.0/). 